\title{
Rights of Elderly in Thailand: Policy Dimension
}

\author{
Rotjanaporn Rungrueang ${ }^{1}$, and Chen $\mathrm{He}^{2}$ \\ ${ }^{1} \mathrm{PhD}$. Student in College of Public Administration, Huazhong University of Science and Technology \\ ${ }^{2}$ Professor and Supervisor in College of Public Administration, Huazhong University of \\ Science and Technology
}

\begin{abstract}
There are 9.6 million people who are over 60 years old, which accounted for $14 \%$ of the total population in Thailand. In the next 10-20 years, Thailand is going to be the "aged society". At present, there is the policy, plan and mechanism of operation for the elderly, especially the policy to define the rights of elderly in various aspects. This research aimed to study the current state of the elderly in Thailand and investigate the policy concerned with the rights of elderly in Thailand. Results showed that the number of elderly in Thailand had increased gradually which led to the change of age and gender structure of population. Consequently, population structure became the inverted pyramid which meant the child and working age population decreased whereas the elderly increased. Thailand set the policy for the rights of elderly in various aspects. Besides, government agencies announced the Notification of the Ministry and the regulations to assure the rights of elderly.
\end{abstract}

Keywords: Rights of Elderly, Elderly, Policy

\section{Introduction}

Number of the elderly has increased currently and the global society is going to encounter the aged society. United Nations and World Health Organization give the definition of "Elderly" as the person who are over 60 years old (Nation, 2007; World Health Organization, 2007). From the situation and the possibility of population structure, it is found that the ratio of elderly worldwide has increased rapidly. It is likely that the number of 600 million elderly will increase to 1.2 billion and 2 billion in 2020 and 2050 respectively (World population ageing, 2009). In the contrary, the birth rate decreases (State Planning Organization, 2007).

Thailand has operated the matter regarding the elderly for a long time. One of the key operation is the movement of United Nations concerning the elderly. The key situation that is regarded the starting point of elderly policy in Thailand is that United Nations organized the conference "World Assembly on Aging" in 1982 which suggested the nations to set the national policy and elderly structure (Piyakorn, 2011). Although Thailand does not regard the readiness for age society as the national issue, the increase of elderly population each year is significant and the government sector should be aware of and set the measure to enhance quality of life of the elderly (Suthin, 1998). Currently, Thailand set the policy, plan and mechanis m for operation for the elderly, particularly the policy that defines the rights of elderly. With this reasons, the researcher was interested in studying the current state of the elderly in Thailand and investigating the relevant policies to the rights of elderly in Thailand.

\section{Research Methodology}

The research methodology is the strategy for finding answer to research purpose. In this research chooses the qualitative method. The researchers of public administration, administrative science, and political science have acceptance qualitative method to do research (Northrop and Kraemer, 1982). Usually, there are two reasons why the researchers of public administration do qualitative research are help to search for knowledge and help to engage personally and meaningfully with operator (Larry, 2010).

The method of study is documentary analysis. The documentary analysis can be conceptualised as three linked processes including data reduction, data display and conclusion drawing (Miles and Huberman, 1984). Significant documentary analysis, such as a proposal, annual report, book, artic le, policy, plan, act of parliament, announcement, news, and other internal documents were collected. Furthermore, an organisational record, 
survey data, charts were gathered for study. The researcher selects and identifies essential or relevant data (David, 2013). Document analys is as a process during data collection is interim after data collection as the final output. In addition, this process occurs before data collection, during study planning and study design (Miles and Huberman, 1994). The collect data is not just the purpose of doing research, but also to analyze them and identify conceptual framework in the study. Thus, the researcher should describes how analyzed and presents the data which unbiased manner in order to obtain true results. The data were collected, the process of data analysis began, involving analysis, interpretation, and presentation of findings (Patton, 1990).

\section{Result}

Thailand has become the aged society since 2005 as a result of the decrease of birth rate (Foundation of Thai Gerontology Research and Development Institute, 2013) and numbers of child and working age population and the gradual increase of elderly numbers. In the past 40 years, Thailand has been very successful in population policy that emphasizing on birth control by changing the attitude towards having the child; that was to say, focusing more on "quality" than "quantity". It led to the change of age and gender structure of population and, finally, formed the inverted pyramid (Jantana, 2013) as shown in Fig. 1.

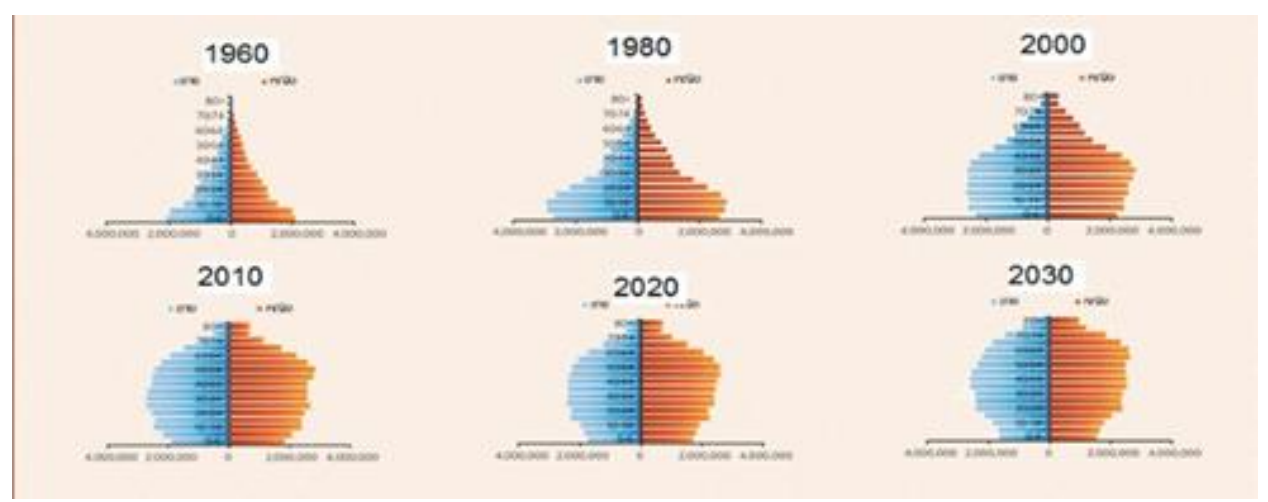

Fig. 1: "Population Pyramid of Thai Population 1960 - 2030"

In 2013, Thailand had 9.6 million population who were over 60 years old, which accounted for $14 \%$ of total population. In the next 10-20 years, Thailand will become the "aged society". United Nation defined the aged society when the ratio of population who were over 60 years old increased to $20 \%$ and over 65 years old increased to $14 \%$ (United Nations, 2002). In 2018, it will be the history of Thailand to have the elderly more than the children, which the ratio of the elderly will be $1 / 5$ of the total population.

The result of study on the policies relevant to the rights of elderly in Thailand revealed that Thailand defined the rights of elderly as determined in the policies and laws. Constitution of The Kingdom of Thailand 2007 Section 40 item 6 stating the rights of elderly to be protected in the suitable judiciary. Furthermore, they had the rights to be treated appropriately in the case of sexual violence. Section 53 stated about the rights of people who are over 60 years old who had insufficient income for living to receive the welfare and public facilities as deserved as well as to receive the suitable aids from the government. Section 80 item 1 stated about the rights of elderly to receive the welfare and aids to better their quality of life and self-reliance. Declaration on Thailand's older persons 1999, which was approved by the cabinet on 23 March 1999, was the obligation to enhance the quality of life of elderly and to protect the rights. The key contents relevant to the rights of elderly were defined in item 1 and 8 that the elderly should receive the basic element for living as deserved, be protected from the abandonment and infringement equally, particularly the elderly who could not support themselves or family. Besides, the government should legis late the law for the elderly to ensure and enforce to protect and prevent the welfare for the elderly by having the participation of private and public sector as well as the social organizations. The Eleventh National Economic and Social Development Plan $(2012$ - 2016) stated the rights of elderly in Strategy 1: Strategy of social justice and Strategy 2: Strategy of human development to the sustainable learning society. It could be concluded that in regard to social services, it promoted everyone to have the basic rights, to have saving to assure the stability and to strengthen all sectors, provides more choices for living and creates the social and economic as well as political participation as deserved. Moreover, it created the opportunity for elderly participation in activities, developed the elderly to have economic and social stability, allowed the elderly 
to adjust themselves to suit the changes. It also promoted the income and job distribution to the elderly by characterizing the appropriate jobs and wage rate along with educating knowledge to the elderly to apply it to community and country development. The elderly should be promoted to have self-reliance by developing the physical environment and requirement to suit the age level. Moreover, caring system for elderly should be various and the development of potential community to become the model of elderly caring is required to expand to other communities. The Act on the Elderly, 2003 A.D. defined that the elderly had the rights to be protected in 13 aspects i.e. Medical and public health services that facilitate the elderly specially, Education, religions and useful information and news for their living, Appropriate occupations or occupational training, Self-development and participation in social activities, grouping together as a network or community, Facilities and safety directly rendered to the elderly in buildings, places, vehic les or other public services, Appropriate support for transport fares, Exemption from entry fees to government places, Assistance for any elderly person facing danger of torture or unlawful exploitation or abandonment, Provis ion of advice and consultation on other proceedings in connection with a case or the remedy of family problems, Extensive provision of housing, food and clothing where necessary, Extensive and fair provision of monthly old-age pension, Assistance in holding their traditional funerals and Other matters stipulated by the Committee in an announcement (LMI, 2014). The declaration of the current Prime Minister on Friday, 12 September 2014 that contained the policy regarding the rights of elderly in regard to the decrease of social class and the creation of accessibility of government services by promoting the quality of life and appropriate employment or activities, promoting house care system, sanitarium and hospital for elderly, including developing the financial system for elderly care. Thailand's 3rd National Human Rights Plan (2014-2018), it was stated to increase the potential of healthy elderly to have education, especially in information technology, to develop medical and public health sciences and technology to upgrade the quality of life of elderly, to offer appropriate job for the elderly and extend the retirement period for the necessary position, to enhance the potential of older fund and focus on the public relations, to promote the readiness of the country and the elderly to enter the aged society efficiently, to promote long-term elderly care and well as to develop the disadvantaged elderly care system, to create national financial policy to be ready for the aged society and develop the economic insurance for elderly and to set the facilities for the elderly to receive the special rights from public transportation (RIPD, 2013). The 2nd National Plan on the Elderly 20022021, 1st Revision 2009 promoted the government, society and community to aid the elderly to live as deserved by stating the rights of the elderly in the income and employment, protection, education and residence, public health as well as the organization for elderly.

Furthermore, it was found that the government agencies of Thailand i.e. Ministry of Public Health, Ministry of Social Development and Human Security, Ministry of Culture, Ministry of Transport, Ministry of Justice, Ministry of Natural Resources and Environment, Ministry of Education, Ministry of Labor, Ministry of Touris m and Sports, Ministry of the Interior and Ministry of Finance announced the Notification of the Ministry and the regulations to ensure the rights of elderly which could be concluded (Kusol, 2007) as follows. There was a special path for the elderly and the elderly clinic in the hospital, the activities to promote health and recreation, the promotion of occupation to the elderly, the website for health information for the elderly, the facilities and safety for elderly in the public services, the aid for transportation fares and the exemption from entry fees to government places, the extensive provision of housing, food and clothing where necessary, the extensive and fair provision of monthly old-age pension, assistance in holding their traditional funerals, the information center for consulting, the older fund for tax exemption, the tax exemption for the supporter of the elderly who had no income to have rights for tax deduction.

\section{Conclusion}

Thailand had become the aged society since 2005 because the child and working aged population decreased while the elderly people increased. In 2013, Thailand had 9.6 million population who were over 60 years old, accounted for $14 \%$ of total population. Besides, it was likely that 2018 would be the first year that the number of elderly would be higher than child population. Thailand had determined the rights of elderly that were evidenced in policies and laws: Constitution of The Kingdom of Thailand 2007, Declaration of Elderly 1999, The Eleventh National Economic and Social Development Plan (2012 - 2016), The declaration of the current Prime Minister on Friday, 12 September 2014, The Third National Human Rights Plan (2014-2018) and The 2nd National Plan on the Elderly 2002-2021, 1st Revision 2009. Further, government agencies announced the Notification of the 
Ministry and the regulations to ensure the rights of elderly i.e. Ministry of Public Health, Ministry of Social Development and Human Security, Ministry of Culture, Ministry of Transport, Ministry of Justice, Ministry of Natural Resources and Environment, Ministry of Education, Ministry of Labor, Ministry of Tourism and Sports, Ministry of the Interior and Ministry of Finance.

\section{Acknowledgements}

I really appreciate to my $\mathrm{PhD}$ supervisor Professor Chen He for supporting.

\section{References}

[1] David E. McNabb. Research Methods in Public Administration and Nonprofit Management Quantitative and Qualitative Approaches, 3rd ed. New York: M.E. Sharpe, 2013

[2] Foundation of Thai Gerontology Research and Develop ment Institute (TGRI). Situation of Thai Elderly 2013. Bangkok: Amarin Printing \& Publishing Public Company Limited, 2013

[3] Jantana, Sitthiworanan. The effective of Demographic Change in Thailand. Aging organization, Bangkok: BMA Training and Development, 2013, p 1.

[4] Kusol Soonthorndhada. (August-September 2007). The right of elderly law. Institute for population and social research [Online].27(6). Available: http://www.popterms.mahidol.ac.th/newsletter/showarticle.php?articleid=54

[5] Labor Market Research Division (LMI). Role of local government organisation in a promoting elderly employment. Bangkok: Labor Market Research Division, 2014, p 23.

[6] Larry S. Luton. Qualitative Research Approsches for Public administration. New York: M.E.Sharpe, 2010

[7] Miles, M.B. and Huberman, A.M. Qualitative Data Analysis: A Sourcebook of New Methods. Beverly Hills, California: Sage, 1984

[8] Miles, M.B. and Huberman, A.M. Qualitative Data Analysis: A New Sourcebook of New Methods. Beverly Hills, California: Sage, 1994

[9] Northrop, Alana and Kenneth L. Kraemer, "Contributions of Political Sceince and Public Admin istration to Qualitative Research Methods," in Qualitative Methods for Institutional Research, Eileen Kuhns and S.V. Martorana, eds. San Francisco, Jossey-Bass, 1982, pp. 43-45.

[10] Patton, Michael Quinn. Qualitative Education and Research Method. Newbury Park, CA: Sage, 1990

[11] Piyakorn, Wangmahaporn. Government policies and future directions of social service provided to old-aged people in Thailand. Bangkok: SP Printing Massproduct, 2011

[12] Population Division, United Nations. (August 2009). World Population Ageing. New York: United Nations [Online]. Available: http://unorg/esa/populations/Worldageing

[13] Population Division, United Nations. (December 2009). World Population Ageing. New York: United Nations [Online] . Available: http://www.un.org/esa/population/publications/WPA2009/WPA2009_ WorkingPaper.pdf

[14] State Planning Organization. The Situation of Elderly People in Turkey and National Plan of Action on Ageing. Turkey: WHO Press, 2007

[15] Suthin, On-ubon, "Factors affecting the needs for social welfare services of the elderly in rural areas,", M.S. thesis, Dept. Sociology., Khon Kaen Univ., Chaiyaphum, Thailand, 1998.

[16] United Nations. (April 2002). Report for Madrid Meeting on World Aging. New York: United Nations [Online]. Available: http://www.un.org/esa/population/publications/worldgeing 19502050/

[17] United Nations. (2007). World Economic and Social Survey 2007, Development in an Aging World. New

York: United Nations Publishing Section [Online]. Available: http://www.un.org/esa/policy/wess/wess 2007files/wess 2007.pdf

[18] World Health Organization. WHO Global Report on Falls Prevention in Older Age. Switzerland:

WHO Press, 2007 